\title{
Awareness and Knowledge on Epilepsy Among Undergraduate Medical Students in Pakistan

Syed Arsalan Ahmed ${ }^{1}$, Ahmed Faraz', Mohammad Adil Ramzan², Saleema Fateema1, Nabeeha Essam ${ }^{3}$, Shahraiz Shah Rizvi1, Muhammad Tahir Chohan ${ }^{2}$, Taha Nafees ${ }^{1}$, Ghulam Ishaq Khan ${ }^{4}$

\section{Abstract}

Background: Epilepsy is a common neurological disorder which affects millions of people throughout the world. However, it has been discovered that there is a great degree of ignorance regarding the science of epilepsy among the general masses as well as the populace of medical students. Studies have been conducted whose results have shown that, there has been fabrication regarding the clinical presentation \& treatment of epilepsy among the common man. Numerous appear to link epilepsy to evil spirits and possession that can be healed by spiritual treatments by certain specialists given the designations of 'demonologists', 'paranormal investigators' or 'mystics'. In such circumstances, medical students can prove to be a major source to educate the society at large. Therefore, it is crucial that their knowledge \& attitude towards epilepsy is accurate and thus, must be evaluated at an early stage in their medical career, so that these future physicians may play a pivotal role in the public awareness of epilepsy.

Method: This study was conducted in Pakistan, at a Government sector medical college, namely, Karachi Medical and Dental College. This is a cross-sectional study. Data was collected between October to December of the year 2014. 270 medical students were given the KAP (knowledge, attitude \& practice) form of epilepsy to fill out. The software used to interpret and tabulate the results was SPSS v.16 for Windows. The chi-square test was employed to determine the proportion of knowledge of epilepsy among medical students. The p-value calculated was equal to 0.05 .

Findings: In this study, 270 medical students were recruited, of which 90 were males (33.3\%) where as 180 were females (66.6\%). The ages of the student participants were within the range of 18
1 Karachi Medical and Dental College, Karachi, Pakistan.

2 Abbasi Shaheed Hospital, Karachi, Pakistan.

3 Sindh Medical College,Karachi, Pakistan.

4 University of Arkansas for Medical Sciences, Arkansas, USA.

Contact information:

Syed Arsalan Ahmed.

झ sarsalan.zaidi@gmail.com 
to 24 years. The analysis of our study demonstrates that: $85.1 \%$ of the medical students consider epilepsy to be a neurological disorder; $6.66 \%$ believe epilepsy is an infectious disease; $4.44 \%$ believe it to be a hereditary disease, whereas, $3.7 \%$ of the students reckon it is a psychiatric illness. Generalized tonic clonic seizures was deemed to be the most common form of epilepsy $(25.5 \%)$ with complex partial seizures being the least common form (1.85\%), as well as relatively unknown by the students.

It was discovered through this study that, students were much less acquainted with the knowledge regarding the treatment of the disorder: multiple drug therapy was considered as the treatment by $56.66 \%$ of the students, spiritual treatment by $3.7 \%$, spiritual treatment with medication by $20 \%$, surgical treatment by $17.4 \% \& 2.22 \%$ deemed epilepsy as a self limiting disease.

Conclusion: It has been observed with this survey that the medical students of Pakistan are well aware of the knowledge of epilepsy and it being a medical condition. However, the students need to be educated early on in their training to be physicians, about certain aspects and details of the neurological disorder, for instance, the appropriate treatment of epilepsy, where their knowledge is lacking.

\author{
Keywords \\ Epilepsy, Knowledge , \\ Undergraduate, Medical \\ students, Pakistan.
}

\section{Introduction}

Epilepsy is one of the commonest neurological disorders with marked sociocultural stigma [1]. It is a neurodegenerative disease manifesting as seizures that lack any toxic grounds. According to the 2012 WHO factsheet, epilepsy afflicts 50 million people all over the world, almost $80 \%$ of whom belong to developing countries and nearly three fourths of these patients do not receive the appropriate treatment [2]. Further studies have reported the global incidence of epilepsy to be generally between 5 to 10 cases per 1000 people. The allinclusive rate includes the incidence of 50 people per 100,000 persons and these incidences are multifactorial that vary according to the seizure types, seizure presentation and anti epileptic drugs administered. [3] To date, there has been very little in- put towards epilepsy in Pakistan despite a striking prevalence rate of 9.9 people in 1000 persons, among which $74.3 \%$ epileptics are aged less than 19 years [4]. In Pakistan a high male to female ratio of epilepsy of about 3:1 has been observed as well [5].

There is a great degree of ignorance and unawareness associated with epilepsy amongst the medical as well as non- medical individuals at large. The metaphysical (i.e. supernatural) associations that are often linked with epileptics affect the quality of life of such patients,more than the affliction itself and also generate negative attitudes and prejudice on individuals with epilepsy [6]. In the Southeast Asian region, a multitude of myths exist traumatizing not only the patient but also the patient's family. The patient is considered to be possessed by 
evil spirits, and the seizures are regarded as contagious. It has gone as far as women being deemed as infertile and many epileptics are sent to lunatic asylums for the rest of their lives, as epilepsy is misunderstood to be a form of insanity in many areas of the Southeast Asian region specifically India, Sri Lanka and Indonesia [7]. These factors greatly affect the professional as well as marital lives of these individuals by deprivation from employment opportunities and marriages [7]. School going children also suffer due to lack of knowledge and improper attitude of teachers towards epilepsy [8, 9]. This causes banishment of such individuals and these patients are forced to suffer from isolation, disgrace and low self-esteem,particularly in developing countries and lower class societies where a general misperception of epilepsy prevails $[6,10]$.

Young medical students are the future physicians of society and during their undergraduate period, they can be a source of health awareness and opinion formers to the general population. For this purpose, their knowledge must be assessed so they may play a pivotal role in society to educate the populace regarding various diseases. Therefore we came forward with an objective to determine an average estimate of medical students acquainted with the knowledge of epilepsy. We also verified as to whether these students held a similar stigma towards epileptics as the general population. Most medical students are aware of the fact that stigmatizing epileptics is false and has no scientific grounds [11]. Yet they encounter individuals who hold firm beliefs of supernatural associations with epileptics. As future health care providers, they should be trained appropriately to deal with situations which might put the patients' psychological conditions at stake due to social burden [1]. Hence, prompt steps to spread awareness among the population include the proper attitude and understanding of medical professionals towards epileptic patients as well as counseling of common man so as to improve their approach towards epileptics because eradicating ignorant beliefs and practices is essential to improving the quality of life of these patients.

\section{Methods}

This is a cross sectional study conducted at the Karachi Medical and Dental College (K.M. \& D.C.), Pakistan, which is a public sector institution and the scheme of education followed, is the Professional System. The data was collected from January 2014 to March 2014. The total number of students that participated in the study was 270 , from first through final year of medical school. All the students were handed a self administered KAP (knowledge, attitude and perception) questionnaire. The questionnaire required basic information such as age, gender, income and tested the students' knowledge of epilepsy, its clinical relevance, their attitude towards epilepsy and their ethical responsibility towards epileptics.

The statistical analysis was performed with SPSS v.16 for Windows and chi-square test was employed to determine the proportion of knowledge of epilepsy among medical students. The $p$-value calculated was equal to 0.05 .

\section{Results}

The total number of students recruited in our study was 270, 90 (33.3\%) of whom were males and 180 $(66.6 \%)$ were females. The age of students varied between 18 and 24, the majority of whom were aged 20 years $(30.4 \%)$ (Table 1$)$. Of the total population of students, $85.1 \%(n=230)$ were aware of the fact that epilepsy is a neurological disorder, $6.66 \%(n=18)$ of students believed it to be an infectious disease, $4.44 \%(n=12)$ considered it a hereditary disease whereas $3.7 \%(n=10)$ regarded it as a psychiatric illness (Table 2). Electronic media was considered as a fitting source of knowledge about epilepsy by only $13.7 \%(n=37)$ of students and $44.07 \%$ of students had never seen an epileptic patient (Table 3 ). With regards to the types of epileptic seizures known to medical students, an 
Table 1. Frequency of knowledge \& the concept of epilepsy among medical students according to gender and age.

\begin{tabular}{|l|c|c|}
\hline Gender & Frequency & Percentage \\
\hline Male & 90 & $33.3 \%$ \\
\hline Female & 180 & $66.6 \%$ \\
\hline Age & & \\
\hline 18 & 8 & 3.0 \\
\hline 19 & 32 & 11.9 \\
\hline 20 & 82 & 30.4 \\
\hline 21 & 50 & 18.5 \\
\hline 22 & 50 & 18.5 \\
\hline 23 & 36 & 13.3 \\
\hline 24 & 12 & 4.4 \\
\hline
\end{tabular}

Table 2. Type of disease epilepsy was catergorized as by the medical students.

\begin{tabular}{|l|c|c|}
\hline & Frequency & Percentage \\
\hline Neurological disease & 230 & $85.1 \%$ \\
\hline Hereditary disease & 12 & $4.44 \%$ \\
\hline Psychiatric disease & 10 & $3.7 \%$ \\
\hline Infectious disease & 18 & $6.66 \%$ \\
\hline
\end{tabular}

Table 3. Media as an educational tool \& witnessing of an epileptic seizure by the medical students.

\begin{tabular}{l|c|c|}
\hline $\begin{array}{l}\text { Students who consider } \\
\text { media as source of } \\
\text { education for epilepsy }\end{array}$ & Frequency & Percentage \\
\hline $\begin{array}{l}\text { Students who do not } \\
\text { consider media as source } \\
\text { of education for epilepsy }\end{array}$ & 233 & $13.7 \%$ \\
\hline $\begin{array}{l}\text { Students who have } \\
\text { witnessed an epileptic } \\
\text { seizure }\end{array}$ & 151 & $56.9 \%$ \\
$\begin{array}{l}\text { Students who have never } \\
\text { witnessed an epileptic } \\
\text { seizure }\end{array}$ & 119 & $44.07 \%$ \\
\hline
\end{tabular}

alarming rate of $54.4 \%(n=147)$ students claimed to having no knowledge. Nevertheless, 25.5\%, 5.18\%, $4.07 \%, 1.85 \%$ and $8.88 \%$ were acquainted with the knowledge of tonic clonic seizures, absence seizures, atonic seizures, complex partial seizures and simple partial seizures respectively (Table 4). Stigmatization of epileptics by medical students varied on different levels. Albeit $94.7 \%$ of students did not consider epilepsy as a supernatural phenomenon and $88.8 \%$ believed that epileptics were capable of leading a healthy marital and parental life, $54.07 \%$ of students claimed to consider epilepsy as a hindrance in receiving education and $62.5 \%$ admitted that they wouldn't allow a family member's marriage to an epileptic. A significant rate of $71.8 \%$ of students agreed that epilepsy cannot cause malformation of the fetus in epileptic mothers (Table 5). The students' knowledge of diagnostic criteria was tested and it revealed that 55.2\% believed EEG as the appropriate tool for diagnosis instead of CT, MRI and PET scan. Multiple drug therapy as opposed to mono drug therapy for epileptics was considered as the treatment of choice by $68.8 \%$ of students. Spiritual (religious) treatment was regarded by 3.7\% of students, spiritual treatment with medication was considered by $20 \%$ of students whereas $2.22 \%$ of students deemed epilepsy as a self limiting disease and $17.4 \%$ considered surgical treatment. Prolonged and emergency seizures were regarded as controllable by $87.4 \%$ of students (Table 6 ).

Table 4. Types of epileptic seizures known among the medical students.

\begin{tabular}{|l|c|c|}
\hline & Frequency & Percentage \\
\hline Simple partial seizures & 24 & $8.88 \%$ \\
\hline Tonic clonic seizures & 69 & $25.55 \%$ \\
\hline Atonic seizures & 11 & $4.07 \%$ \\
\hline $\begin{array}{l}\text { Complex partial seizures } \\
\text { Absence seizures }\end{array}$ & 05 & $1.85 \%$ \\
\hline $\begin{array}{l}\text { No knowledge of any type } \\
\text { of seizure }\end{array}$ & 14 & $5.18 \%$ \\
\hline
\end{tabular}


Table 5. Personal view of the medical students regarding certain misconceptions and aspects in relation to epilepsy.

\begin{tabular}{l|c|c|} 
& Frequency & Percentage \\
\hline $\begin{array}{l}\text { Students who do not } \\
\text { consider epilepsy as a } \\
\text { Supernatural phenomenon } \\
\text { Students who consider that } \\
\text { epileptics can lead a healthy } \\
\text { marital \& parental life }\end{array}$ & 240 & $94.7 \%$ \\
\hline $\begin{array}{l}\text { Students who consider } \\
\text { that epilepsy affects the } \\
\text { education of a person }\end{array}$ & 240 & $88.8 \%$ \\
\hline $\begin{array}{l}\text { Students who will not } \\
\text { allow a family member to } \\
\text { marry an epileptic patient }\end{array}$ & 146 & $54.07 \%$ \\
\hline $\begin{array}{l}\text { Students who believe that } \\
\text { epilepsy does not cause } \\
\text { malformations in fetuses }\end{array}$ & & \\
\hline
\end{tabular}

Table 6. Diagnostic and treatment options considered by medical students.

\begin{tabular}{|c|c|c|}
\hline & Frequency & Percentage \\
\hline $\begin{array}{l}\text { Students-plural form } \\
\text { who consider Eeg as a } \\
\text { diagnostic tool }\end{array}$ & 149 & $55.2 \%$ \\
\hline $\begin{array}{l}\text { Students who consider } \\
\text { Brain imaging (CT, MRI, } \\
\text { PET Scan) as a diagnostic } \\
\text { tool }\end{array}$ & 121 & $44.8 \%$ \\
\hline $\begin{array}{l}\text { Students who consider } \\
\text { drug therapy as the } \\
\text { treatment option }\end{array}$ & 153 & $56.66 \%$ \\
\hline $\begin{array}{l}\text { Spiritual/Religious } \\
\text { treatment }\end{array}$ & 10 & $3.7 \%$ \\
\hline $\begin{array}{l}\text { Spiritual /Religious } \\
\text { treatment along with } \\
\text { pharmacotherapy }\end{array}$ & 54 & $20 \%$ \\
\hline Self limiting disease & 06 & $2.22 \%$ \\
\hline Surgical treatment & 47 & $17.4 \%$ \\
\hline $\begin{array}{l}\text { Students that consider } \\
\text { seizures cannot be stopped } \\
\text { at emergency }\end{array}$ & 34 & $12.59 \%$ \\
\hline $\begin{array}{l}\text { Students who consider } \\
\text { seizures can be stopped at } \\
\text { emergency }\end{array}$ & 236 & $87.4 \%$ \\
\hline
\end{tabular}

\section{Discussion}

This survey was performed on the medical students of a public sector medical college of Pakistan (K.M. \& D.C.), to assess their familiarity, knowledge \& attitude towards epilepsy at the initial stages of their medical career, since it will be the task of these medical students to provide care to these epileptic patients in the future. Although the results do not represent the medical students of Pakistan in entirety, it gives an insight into one group of under graduates in Pakistan regarding their knowledge and attitude towards epilepsy. Population based surveys show that knowledge of epilepsy is generally superior among people with higher socioeconomic status and better educated individuals (university and grad school students). It has also been evaluated through a variety of studies that, in comparison, health care students of various countries in the world (Brazil, India, Italy, Canada) have more knowledge of epilepsy [12, 13, 14, 15, 16].

In our study we interviewed, 90 males \& 180 females of a public sector medical college, in which $85.1 \%$ students consider epilepsy as a neurological disease as compared to a study performed on undergraduate medical students of Brazil, where 93.4\% consider epilepsy as a brain disease [16], and an Indian study showed students who consider epilepsy as a neurological disease by $93.1 \%$ [11]. Although many students recognize brain disease as a cause of seizure, in an Italian study, $45 \%$ of the medical students perceived epilepsy as psychiatric illness, in a Malaysian study $39.7 \%$ of the undergraduate students regarded epilepsy as a mental illness, where as in our study this value is $3.7 \%$ [15].

On questioning the medical students about the specific types of epileptic seizure, about $54.4 \%$ of students had no knowledge regarding this. For those students who had a fundamental idea of the types of epilepsy, tonic clonic seizures were recognized as the most common type of epilepsy to their knowledge. This result is quite similar to a study 
conducted in Thailand where 91.5\% were aware that tonic clonic seizures are more common [11]. Absence seizures are least commonly known in the Thai study [11], where as in our study, complex seizures are least known among medical students, creating a difference of opinion.

Epilepsy is a chronic disease which requires proper treatment \& management. Undergraduates being future medical practitioners must be evaluated at an early stage of their career regarding this aspect. When medical undergraduates were asked about the treatment of epilepsy, about $56.66 \%$ medical students responded that epilepsy is treated by medications, a similar study in Brazil shows that 93\% of medical students are aware that epilepsy requires treatment by allopathic medications [16], this comparison shows that the medical undergraduates in this study group lack essential information concerning the drug treatment for epilepsy, and must be trained accordingly.

In relation to this group of undergraduate healthcare students, $17.4 \%$ of the students believe that surgical treatment relieves epilepsy. This points out to the fact that these medical students must be educated about the surgical options of epilepsy as it has been found that resective surgeries can reduce seizures [17]. Another study shows 44.3\% of patients were seizure free since the baseline visits [18].

$2.22 \%$ of medical students in this study consider it a self limiting disease in comparison to a study in Brazil where $1 \%$ of the students consider it as a self limiting disease [16].

\section{Conclusion}

This study concludes that although this group of medical students is familiar with epilepsy, there are certainly major gaps in their knowledge of this disease. Therefore, it is necessary that, on the whole, the forthcoming future physicians must undergo courses of epilepsy with vigorous discussions to en- hance the level of their education of the disease, and attain the relevant treatment of epileptics in their professional careers.

\section{Acknowledgement}

We would like to acknowledge Dr Asma and Abdul Basit Arif for their part in data collection.

\section{Competing and conflicting Interests}

We declare that we have no conflict of interest.

\section{References}

1. Thomas, SanjeevV, and Aparna Nair. 'Confronting The Stigma Of Epilepsy'. Ann Indian Acad Neurol 14.3 (2011): 158.

2. Who. int. WHO-Epilepsy [Internet]. 2015 [cited 22 April 2015]. Available from: http://www.who.int/mediacentre/factsheets/ fs999/en/

3. Bell G, Sander J. CPD -Education and self-assessment The epidemiology of epilepsy: the size of the problem. Seizure. 2001; 10(4): 306-316.

4. Aziz H, Ali S, Frances $P$, Khan M, Hasan K. Epilepsy in Pakistan: A Population-Based Epidemiologic Study. Epilepsia. 1994; 35(5): 950-958

5. Khatri I A, lannaccone S T, llyas M S, Abdullah M, Saleem S. Epidemiology of Epilepsy in Pakistan: review of literature.J Pak Med Assoc Dec - Dec 2003; 53(12): 594-6.

6. Jacoby A. Stigma, epilepsy, and quality of life. Epilepsy \& Behavior. 2002; 3(6): 10-20.

7. Epilepsy in the WHO South-East Asian Region: bridging the gap [Internet]. 2005 [cited 22 April 2015]. Available from: http:// www.who.int/mental_health/neurology/epilepsy/searo_report. pdf

8. Babikar H, Abbas I. Knowledge, practice and attitude toward epilepsy among primary and secondary school teachers in South Gezira locality, Gezira State, Sudan. J Fam Community Med. 2011; 18(1): 17.

9. Thacker A, Verma A, Ji R, Thacker P, Mishra P. Knowledge awareness and attitude about epilepsy among schoolteachers in India. Seizure. 2008; 17(8): 684-690.

10. Dilorio C, Osborne Shafer P, Letz R, Henry T, Schomer D, Yeager $\mathrm{K}$. The association of stigma with self-management and perceptions of health care among adults with epilepsy. Epilepsy \& Behavior. 2003; 4(3): 259-267.

11. Tiamkao S, Tiamkao S, Auevitchayapat $N$, et al. Basic knowledge of epilepsy among medical students. J Med Assoc Thai. 2007; 90(11): 2271-6. 


\section{INTERNATIONAL ARCHIVES OF MEDICINE

12. Caveness WF, Gallup Jr GH. A survey of public attitudes toward epilepsy in 1979 with an indication of trends over the past thirty years. Epilepsia 1980; 21: 509-18.

13. Iivanainen $M$, Uutela $A$, Vilkkumaa I. Public awareness and attitudes toward epilepsy in Finland. Epilepsia 1980; 21: 413-23

14. Kim MK, Kim IK, Kim BC, Cho KH, Kim SJ, Moon JD. Positive trends of public attitudes toward epilepsy after public education campaign among rural korean residents. J Korean Med Sci 2003; 18: 248-54

15. Mecarelli O, Li Voti P, Vanacore N, D'Arcangelo S, Mingoia M, Pulitano P, Accornero N. A questionnaire study on knowledge of and attitudes toward epilepsy in school children and university students in Rome, Italy. Seizure 2007; 16: 313-9.

16. Falavigna A, Teles A, Roxo M, Velho M, Silva R, Mazzocchin T et al. Awareness and attitudes on epilepsy among undergraduate health care students in Southern Brazil. Journal of Epilepsy and Clinical Neurophysiology. 2009; 15(1).

17. Spencer S, Berg A, Vickrey B, Sperling M, Bazil C, Shinnar S et al. Initial outcomes in the Multicenter Study of Epilepsy Surgery. Neurology. 2003; 61(12): 1680-1685.

18. Bien C, Kurthen M, Baron K, Lux S, Helmstaedter C, Schramm $J$ et al. Long-Term Seizure Outcome and Antiepileptic Drug Treatment in Surgically Treated Temporal Lobe Epilepsy Patients: A Controlled Study. Epilepsia. 2001; 42(11): 1416-1421.

\section{Comment on this article:}

\section{(f) $[$ in $8+\boldsymbol{S} P$}
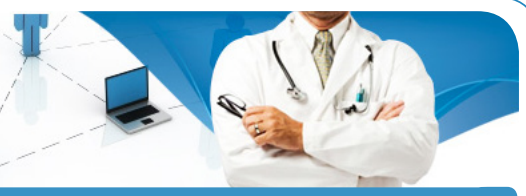

http://medicalia.org/

Where Doctors exchange clinical experiences, review their cases and share clinical knowledge. You can also access lots of medical publications for free. Join Now!

\section{Publish with iMedPub}

http://www.imed.pub

International Archives of Medicine is an open access journal publishing articles encompassing all aspects of medical science and clinical practice. IAM is considered a megajournal with independent sections on all areas of medicine. IAM is a really international journal with authors and board members from all around the world. The journal is widely indexed and classified Q1 in category Medicine. 